\title{
Highly Stressed Elements on Electricity Pylon under Typical Loading Conditions
}

\author{
I. Jusoh \\ Mechanical Engineering Department \\ College of Engineering and Islamic Architecture \\ Umm Al-Qura University, Makkah. \\ Kingdom of Saudi Arabia
}

\begin{abstract}
Frame structure called electricity pylon is needed to transmit electricity from source to it intended location. This structure is constructed with a standard assembly technique and procedure so that it will survive anticipated loadings during it intended service life. During its service life this structure will experiences several type of loadings as well as several combination of loading magnitude that give rise to maximum structural responses. Certain elements within the structure will experience maximum stresses due to external loading as well as loads transferred from adjacent members. In this paper, elements experiences maximum stress responses are identified. The advantage of this finding is that the weak members within the structure can easily be recognized and further action can be taken to study and increase it size or parameters thus improve it related reliability. The result shows that under typical loading condition, element 237 experienced highest combination stress at a magnitude of $424.86 \mathrm{MPa}$.
\end{abstract}

Keywords - electricity pylon, structural modeling, interaction angle, deviation angle, maximum stresses, structural deflection.

\section{INTRODUCTION}

Several type loadings acting on electricity pylon during it service life transmitting power from source to distribution points. Details of these loading were previously discussed by Jusoh et al. [1]. External loads on the structure will induce highest stress response magnitude within certain structural member of the electricity pylon. Service conditions experienced by the structure would determine how critical is the loading and stress level in every element. The main point is that the safety level within the structure must be within the design envelope so that there is no failure or structural collapse occurring under maximum loading environment. One condition usually induce high level of loading on structural member is during the broken wire condition. This broken wire condition effects on electricity pylon was also been specifically addressed by Jusoh [2]. Another loading condition that produce highest stress response within the structure is the deviation angle with respect to wire pull between the pylon plus favorable wind direction acting on the structure.

In this paper, the study focused on structural members or elements that experienced highest magnitude of response from highest loading condition. These members are identified as critical within the structure although there is still large margin of reserve strength. Details of study on loading and response of a typical electricity pylon is in publication [3]. It was found that the maximum loading experienced by the structure is during broken wire conditions that loading would be out of balance due to lost in wire tension and these unbalance loads have to be supported by all members by redistributing to it adjacent members.

Several other basic load cases that show to induced lower stresses in the structure also included in the scope of this paper just for comparison with cases that produced higher combined stresses in structural elements.

\section{MODEL GEOMETRY AND DESCRIPTION}

The structure considered in this study is a frame structure assembled from L-shaped cross-sectional beams as shown in Fig.1. The geometrical configuration is that the base of the structure is measured at $7.064 \mathrm{~m}$ by 7.064 . The frame structure at levels $18.65 \mathrm{~m} 31.81 \mathrm{~m}$ is measured at $1.820 \mathrm{~m} \mathrm{x} 1.820 \mathrm{~m}$. There is an inclination of about 8 degrees angle for the structural legs from ground to elevation of $18.65 \mathrm{~m}$. the purpose of this inclination is to stabilize the structure that enable it to support higher magnitude of overturning moment due to imposed loadings. There are four main horizontal bracing that supports the transmission lines at $18.65 \mathrm{~m}, 23.25$ $\mathrm{m}, 27.85 \mathrm{~m}$ and $31.81 \mathrm{~m}$ with overhanging of $3.54 \mathrm{~m}$ from the vertical members.

Fig. 2 shows a typical L-shape cross-sectioned bar used to assemble in constructing the structure. The structure then modeled using finite element technique thus enable the analysis and simulation be performed yielding anticipated results. Fig.3 shows a structural model with element's number highlighted.

\section{ANALYSIS METHODS}

In this study, static consideration of structural analysis is adopted and it is sufficient to determine the loading effects on the electricity pylon [4]. The environmental loads considered in design can be assumed static or idealized steady wind (quasistatic). The environmental load cases are based on statistical data of wind and ice accretion. They provide a good estimate of the extreme forces that a transmission line is subjected to during its service life [5]. The needs for dynamic analysis is depending on circumstances of accidental loads usually occurred during broken wires condition that produces shock loads. Wind loading sometime is random in nature and having certain frequency that produce dynamic bending.

\section{TYPICAL LOADING CONSIDERATION}

Loadings acting on structure can be associated with several factors such as gravity, wind, earthquake, etc. It was found out that the main source of loading is due to external forces associated to wind load [1], [6]. Directional loadings on transmission structures may also be classified into two main categories namely longitudinal load or transverse load with 


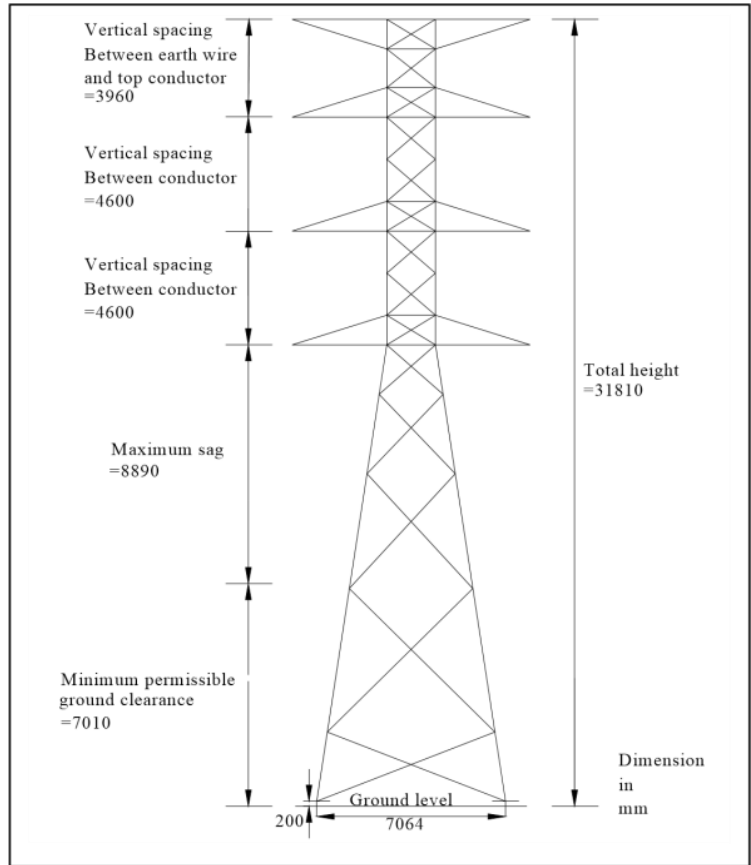

Fig. 1. Typical configuration of electricity pylon.

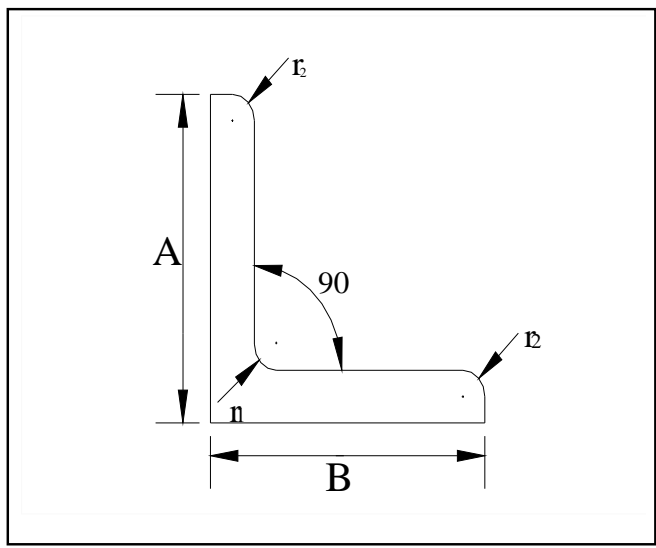

Fig. 2. L-section bar used to form a tower structure

longitudinal load is in the direction of wire linking to another transmission tower [1]. It was found out that wind load is the most dominant source of external loads acting on electricity pylon [6]. Another significant characteristic of this external load is its directionality that will affects the response of the overall stresses within the structural members. In this paper the maximum stresses within the structural members are highlighted and these would indicate the strength utilization as well as indication of safety margin for the structure. Basic wind directions as refer to one structure are transverse and longitudinal directions as discussed in previous publications $[1,2]$.

The results from previous study shows that the structural member of electricity pylon usually experiences maximum high stress during the breaking of transmission lines attached to the structure [2]. Percentage different between highest loading conditions is compared to the normal loading conditions to

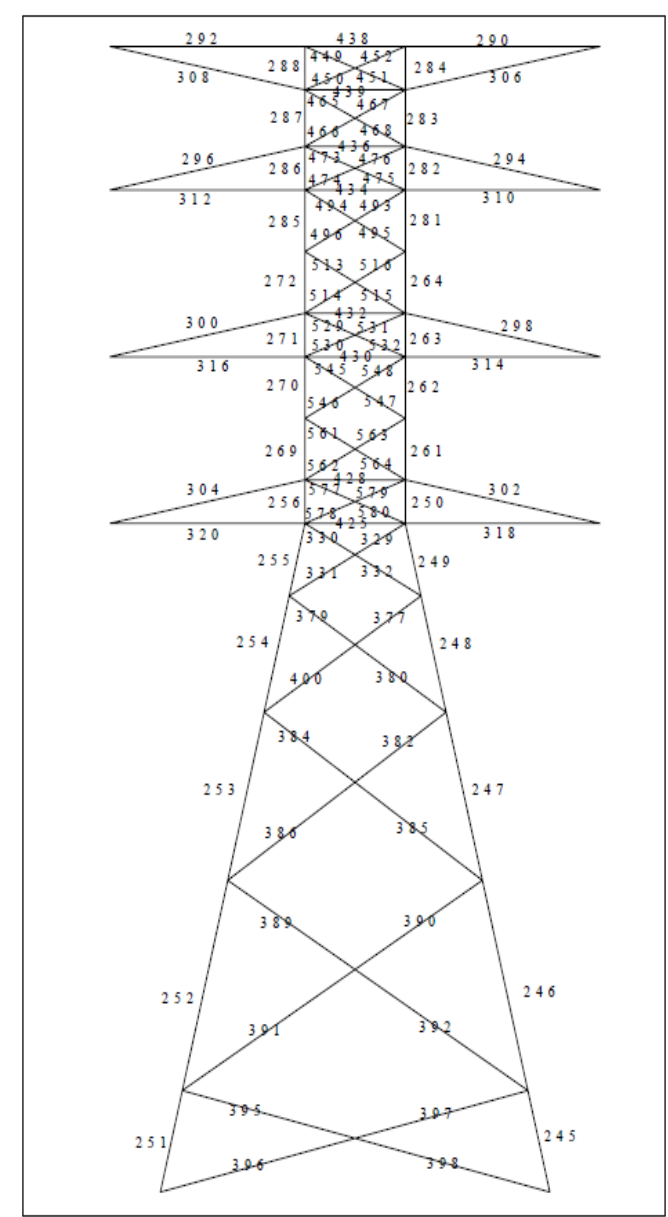

Fig.3 Element number indicated on the structure (front row)

highlight the significant increases of stresses when the unfavorable loading due to broken wires occurred as well as wire lines deviation angle to the electricity pylon.

\section{RESULTS AND DISCUSSION}

The effects of loading onto the electric pylon was investigated and particular attention focused on magnitude of stresses induced within the structure. Elements with significant value of stress are reported in this study. Generally, the result shows that the structure is safe and it is operating with stress utilization of less that it real strength capability. Table 1 shows results of stress and displacement for related load cases.

Basic structural loading experienced by the pylon is due to gravity effect. Under this category, maximum stress occurred on element 298 with a magnitude of $71.34 \mathrm{MPa}$. This is a combination loads due to gravity effects as well as transferred loads from adjacent elements. The normal loading condition assumed that the operational loads is at maximum loading magnitude with wire orientation is longitudinal to the orientation of the pylon. Stress result this loading condition considered in the calculation of percentage stress increases due to other unfavorable loading orientation. Under normal loading condition the elements that experienced maximum stress is element 245 with stress magnitude at $167.95 \mathrm{MPa}$ as shown in Table 1. 
TABLE 1: Stresses and deflections under typical loading conditions.

\begin{tabular}{|c|c|c|c|}
\hline Load Case & $\begin{array}{c}\text { Maximum } \\
\text { Stress } \\
(\mathrm{MPa})\end{array}$ & $\begin{array}{l}\text { Element } \\
\text { Number }\end{array}$ & $\begin{array}{c}\text { Max. } \\
\text { Deflection } \\
(\mathrm{mm})\end{array}$ \\
\hline Gravity Load & 71.34 & 298 & 7.78 \\
\hline Normal Condition & 167.95 & 245 & 92.92 \\
\hline $\begin{array}{l}\text { Wind Load } \\
\text { (i) Transverse } \\
\text { (ii) Longitudinal } \\
\text { (iii) } 45^{\circ} \text { Wind }\end{array}$ & $\begin{array}{l}124.19 \\
106.56 \\
167.95\end{array}$ & $\begin{array}{l}245 \\
390 \\
245\end{array}$ & $\begin{array}{c}107.72 \\
45.81 \\
92.92\end{array}$ \\
\hline Broken wires & 173.12 & 390 & 88.13 \\
\hline $\begin{array}{c}\text { Deviation angle } \\
2 \mathrm{deg} \\
10 \mathrm{deg} \\
30 \mathrm{deg} \\
60 \mathrm{deg} \\
90 \mathrm{deg}\end{array}$ & $\begin{array}{l}105.50 \\
124.19 \\
200.29 \\
316.98 \\
424.86\end{array}$ & $\begin{array}{l}342 \\
245 \\
245 \\
237 \\
237\end{array}$ & $\begin{array}{c}62.87 \\
102.72 \\
180.87 \\
290.68 \\
384.98\end{array}$ \\
\hline
\end{tabular}

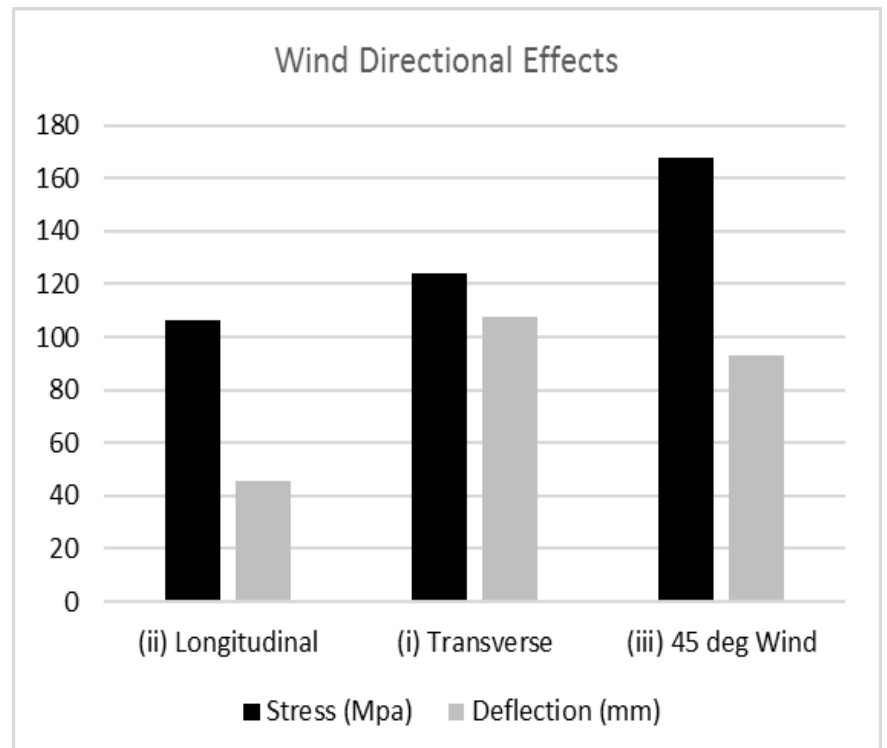

Fig.4. Variation of combination stress and structural deflection in relation to direction of wind loading on the pylon.

Directional wind loading acting on structure and transmission cables attached has variation of responses within the structure, giving maximum combined stress occurred on element 245 with magnitude of $167.95 \mathrm{MPa}$ as shown in Fig.4. Combined maximum stress and deflection are the highest when wind-structure interaction at $45 \mathrm{deg}$ due to the highest aspect ratio related to this direction. During broken wire condition the structure would experiences higher shock loads that will induced higher stress within the structural members. The highest stressed occurred at element 390 with a magnitude of $211.49 \mathrm{MPa}$ when the top and middle conductor wires are broken. This issue has been discussed by Jusoh in ref. [2].

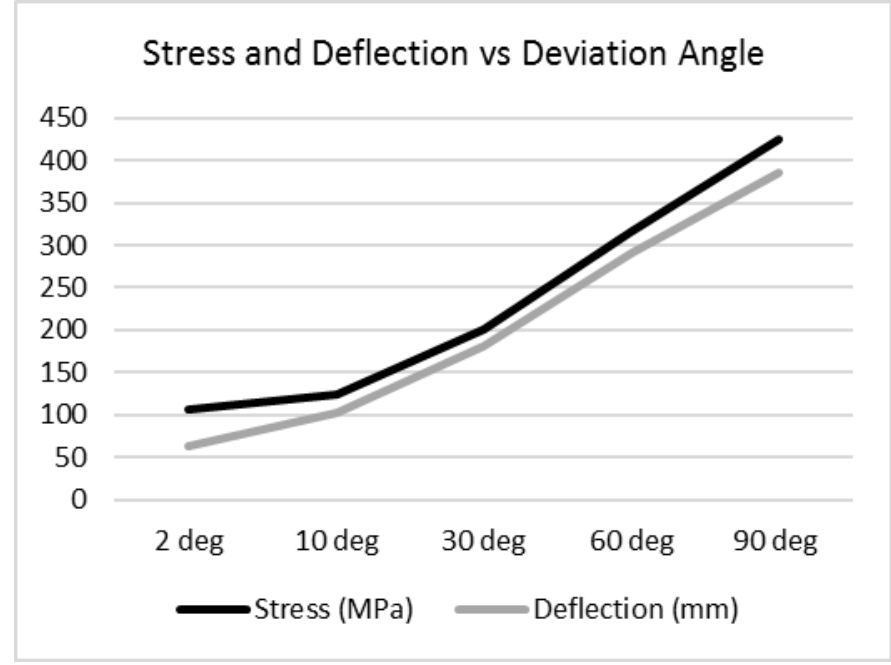

Fig.5. Effects of deviation angle of wire direction to combination stress and structural deflection.

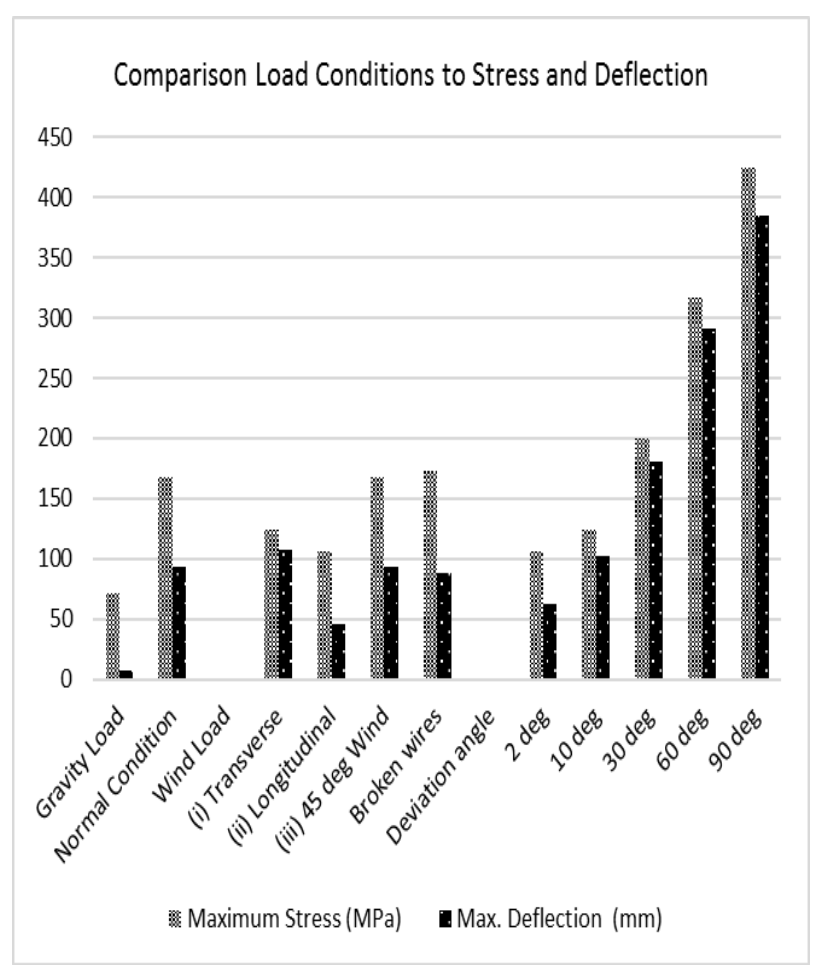

Fig.6. Comparison of significant loading conditions and it related effects on element stress and structural deflection.

Another significant aspect of loading acting on electricity pylon is angle of deviation with respect to wire arrangement to the face of the structure. Fig. 5 shows variation of element stresses and structural deflection in relation to the variation of angle of deviation. It was found that maximum stress ocurred at deviation angle of $90 \mathrm{deg}$. at element 237 with a maximum stress of $424.86 \mathrm{MPa}$. It related maximum deflection at the top of the pylon is $384.95 \mathrm{~mm}$.

Results in Table 1 shows type of loading aspects acting on the structure in relation to maximum combination stresses developed as well as related maximum deflection occurred within the structure. 
Comparison of results related to loading case are presented in this study is shown in Fig.6. Maximum magnitude of stress and deflection occurred for arrangement of wire between the pylon when the angle of deviation is $90 \mathrm{deg}$. Resulting stress is 424.86 MPa and associated deflection is $384.98 \mathrm{~mm}$. During this condition the internal side of the structure experiences compression stresses and the related bending overturning moment is at the highest.

\section{CONCLUSIONS}

The study shows that there is certain variation of responses to several cases of loading experiences by one electricity pylon under typical loading condition during its service life. Generally, conclusions may be outlined as follows;

1. Variation of responses in term of maximum stresses and deflections occurred within the structure.

2. There are several loading cases encountered by the structure namely, basic gravity load, normal/typical loading, directional wind and deviation angle.

3. Maximum stress induced by wind-structure interaction is 167.95 $\mathrm{MPa}$ on element 245 with associated structure deflection of $92.92 \mathrm{~mm}$.

4. Broken wire condition resulting maximum stress of 173.12 $\mathrm{MPa}$ in structural element.

5. The highest combined stress of $424.86 \mathrm{MPa}$ occurred on element 237 under deviation angle loading case.

\section{REFERENCES}

[1] Jusoh, I., Ghulman, H. A., Mandourah, T.S. and Tan,C. C. (2017), "Loading Analysis of a Typical Electricity Pylon", International Journal of Engineering Research and Management, Vol. 4, Issue 10, Oct. 2017.

[2] Jusoh, I. (2017), "Electricity Pylon with Broken Wires Condition", International Journal of Engineering Research and Technology, Vol. 6, Issue 12, Dec 2017.

[3] Jusoh, I. (2018), et. al. "Responses of Electricity Pylon to External Loading". Unpublished.

[4] BS8100 (1986). "Lattice Tower and Mast, Part 1. Code of Practice for Loading." British Standard Institution, London.

[5] McClure, G. and Lapointe, M. (2003). "Modeling the Structural Dynamic Response of Overhead Transmission Lines." Computers \& Structures (2003).

[6] Murthy, S.S. (1990). "Transmission Line Structures." Singapore. McGraw Hill Inc., 1990. 